\title{
Personalized Medicine Implementation with Non-traditional Data Sources: A Conceptual Framework and Survey of the Literature
}

\author{
Casey Overby Taylor ${ }^{1}$, Peter Tarczy-Hornoch² \\ I Department of Medicine, Johns Hopkins University, Baltimore, Maryland, USA \\ 2 Department of Biomedical Informatics and Medical Education, University of Washington, Seattle, \\ Washington, USA
}

\section{Introduction}

Objectives: With the explosive growth in availability of health data captured using non-traditional sources, the goal for this work was to evaluate the current biomedical literature on theorydriven studies investigating approaches that leverage nontraditional data in personalized medicine applications.

Methods: We conducted a literature assessment guided by the personalized medicine unsolicited health information (pUHI) conceptual framework incorporating diffusion of innovations and task-technology fit theories.

Results: The assessment provided an overview of the current literature and highlighted areas for future research. In particular, there is a need for: more research on the relationship between attributes of innovation and of societal structure on adoption; new study designs to enable flexible communication channels; more work to create and study approaches in healthcare settings; and more theory-driven studies with data-driven interventions. Conclusion: This work introduces to an informatics audience an elaboration on personalized medicine implementation with non-traditional data sources by blending it with the pUHI conceptual framework to help explain adoption. We highlight areas to pursue future theory-driven research on personalized medicine applications that leverage non-traditional data sources.

\section{Keywords}

Personalized medicine; implementation science; dissemination research; diffusion of innovation; review literature as topic

Yearb Med Inform 2019:181-9

http://dx.doi.org/10.1055/s-0039-1677916
Personalized medicine is becoming more informed by non-genetic factors with the explosive growth in availability of health data captured using non-traditional sources such as online social networks (e.g., Twitter, online health forums) [1,2], consumer health wearables, and medical devices (e.g., FitBit, smart phone apps) [3-5]. For personalized medicine applications, these health data are promising to complement genetics data in the development of novel algorithms and risk scores that provide a more complete view of patient health and wellness. This is particularly true for complex polygenic diseases that are especially difficult to predict. For those diseases, combining multiple factors such as clinical, demographic, environmental, and genetic data can offer more precise risk predictions [6]. For example, genetic risk scores developed based solely on multiple contributing genetic variants leading to common conditions such as coronary heart disease [7], may be combined with more traditional factors (e.g., family history, conventional risk scores) including from non-traditional sources such as mobile devices to improve the accuracy of risk estimates.

The success of emerging approaches combining genetic and non-genetic factors to advance personalized medicine will depend on our capacity to deploy tools that leverage non-traditional data sources in a timely manner [8]. Mobile data capture has potential to augment traditional approaches such as questionnaires to collecting social factors (e.g., habits and preferences), high frequency data (e.g., movement) and unstructured data (e.g., online activity). Within clinical research, mobile devices are already increasingly deployed to gather patient-reported outcomes and to associate behaviors with clinically informative biomarkers.

There are three areas where approaches that leverage multiple data types are having an impact on personalized medicine. First, healthy individuals are increasingly receiving health data (e.g., direct to consumer genetic testing) that indicate a risk for poor outcomes (e.g., diseases or adverse drug reactions). When health data collection is initiated outside of the clinical setting ("person-generated data" $[9,10])$, from a clinician's perspective they can be characterized as "unsolicited health information." Health care providers will need to ensure that results from unsolicited health information are handled prudently, by addressing the receipt of the results, workflow challenges, and liability issues. Second, combining data from multiple sources has potential to provide a more complete view of the relationship between how health is managed (therapies, lifestyles, etc.) and health outcomes (response to therapy, disease burden, etc.) when assessing risk compared to risk assessments accounting for a single data type alone [6, 11]. Solving the problem of integrating data from multiple sources in risk assessments will have a major impact on personalized medicine by providing a more complete assessment of individual risk for poor outcomes. Third, health assessments based on innovative technologies can lead to population samples that contain bias $[12,13]$ and that can contribute to misestimating health risks in those populations (e.g., GWAS data for genetic risk 
scores [14]). In order to minimize bias, data collection strategies that minimize over or under sampling of a given population (sample disproportionality), especially among racial and ethnic populations, are needed.

The success of personalized medicine depends on translational research of tools based on algorithms and risk scores, including the study of dissemination and implementation with evidence-based genomic applications [15]. Traditional approaches to study algorithms and risk scores draw from data-driven research. Data-driven research [16] involves creating or obtaining sources of data relevant to assessments of health and risk; cleaning, extracting, and annotating data streams to prepare for analyses; integrating, aggregating, and representing data to detect insights; analyzing and modeling data to place insights in context; and interpreting the insights to arrive at solutions. Traditional approaches fail, however, to assess the implementation and dissemination of those solutions with respect to healthcare settings. Implementation science is the study and application of methods to promote adoption of research findings into practice [17]. Dissemination science is the study of how the outputs of implementation science (i.e., evidence-based practices, programs, and policies) can be best communicated to potential adopters and implementers to produce effective results [18]. In order to evaluate implementation and dissemination of new and emerging tools that leverage non-traditional data sources in personalized medicine, theory-driven research is required. Theory-driven research [16] involves: deriving research questions from existing or extended theory; formulating hypotheses to address the questions; designing studies to minimize confounding effects; collecting data using appropriate instruments; and analyzing data to draw inferences.

The objective of this paper is to provide a review of what kinds of theory-driven analyses are being applied to study tools that use non-traditional data sources and their translation into personalized medicine applications. In order to address this objective, we conducted a systematic and concept-centric review of the biomedical literature. We analyzed eight publications in terms of constructs from a conceptual frame- work for technology adoption that we call the personalized medicine unsolicited health information (pUHI) framework. This allows us to understand and structure existing work, as well as to derive future research directions.

\section{Personalized Medicine Unsolicited Health Information Conceptual Framework}

With a focus on implementation and dissemination of personalized medicine solutions that use non-traditional data sources, different models can be drawn from to explain the adoption of information technology. Commonly used to assess technology in health care, are the Technology Acceptance Model (TAM) [19-21] and the Unified Theory of Acceptance and Use of Technology (UTAUT) [22, 23]. The previously used personalized medicine unsolicited health information (pUHI) framework we developed [24] was used to guide the literature review. While other models solely focus on technology adoption, the pUHI framework draws from two theories that allow the investigation of both effective communication of health information and technology: diffusion of innovations (DOI) [25] and task-technology fit (TTF) [26] (see Figure 1). This framework was previously used to guide our study that explored the acceptance of electronic health record (EHR)-embedded clinical decision support to deliver pharmacogenomics information to physicians [24].

Diffusion of innovations [25] theory seeks to evaluate the rate of technology adoption using four key elements to help to explain the "Innovation-Decision Process": innovation (a solution that leverages health data from non-traditional sources), communication channels (processes enabled by the proposed solution), time (when the solution is adopted or rejected and the rate of adoption), and social system (individuals and groups involved in implementation and dissemination strategy decisions for a solution). TTF [26] theory suggests that task-technology fit is achieved by both the tasks the user performs and the character- istics of the technology used. Fit, in turn, leads to utilization and performance impact.

Use of pUHI framework offers many advantages including the ability to identify how, when, and in whom important variables from DOI and TTF theories were measured; the ability to determine what potential sources of variance were evaluated and controlled for; and the ability to extract how and when solutions are successful. Furthermore, DOI and TTF complement each other. The goal for dissemination is broad-based adoption of an intervention, and as such, both diffusion and implementation factors are important. DOI captures dissemination factors including those relevant to the innovation, adopter, social system, individual adoption-process, and diffusion system. TTF captures extent of, quality of, and individual responses to implementation. In addition, it has been highlighted that cultural differences have important implications for perceptions of TTF [27]. Whereas cultural perceptions are not explicitly part of TTF, communication channels and social system elements from DOI can capture those perceptions. For these reasons, we used the pUHI framework to develop the search strategy for the biomedical literature review.

\section{Methods}

Our review is made of three phases. First, we retrieved publications from PubMed that were published between 2014 and 2018 to focus on recently developed and published efforts in the clinical and biomedical literature. The broad keywords and topics used for the search are displayed in Table 1. Keywords and MeSH terms related to non-traditional data sources focused on the data collection tool itself (e.g., the survey instrument), thus, we did not include platforms such as Twitter. The inclusion criteria for screening were as follows: mention of a personal data collection tool; English article; manuscript in peer-reviewed scientific journal; research article; and human participants. The exclusion criteria for full-text reviews were as follows: no study of a tool using non-traditional data; not theory-driven in relation to the use of a tool; and no genomic medicine application. 


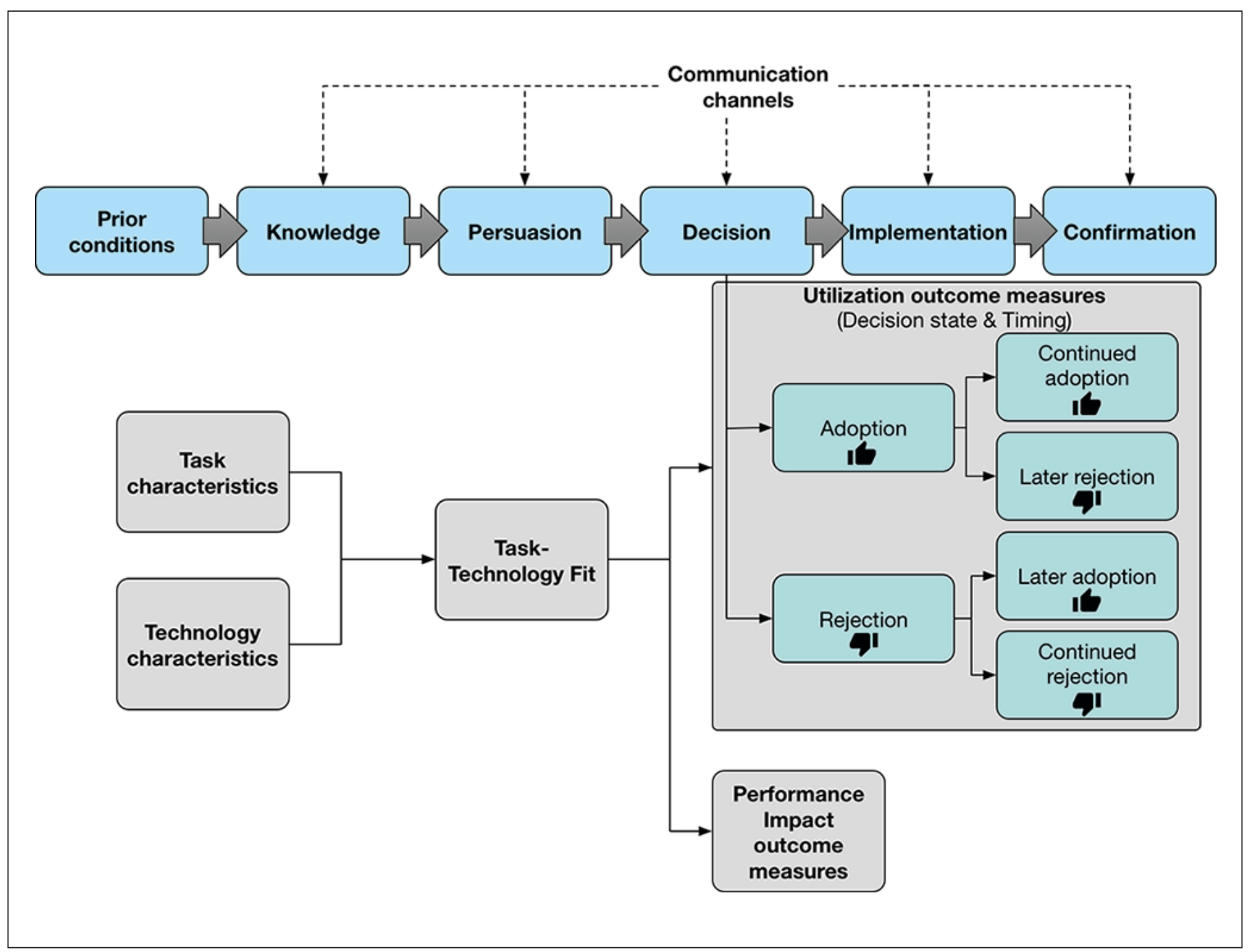

Fig. 1 Personalized medicine unsolicited health information (pUHI) framework to interpret theory-driven studies on tools that use non-traditional data in personalized medicine applications, relative to innovation attributes, social system, communication channels, and task-technology fit of the technologies.

Table 1 Terms and filters used in the search.

\begin{tabular}{|c|c|c|c|c|}
\hline $\begin{array}{l}\text { Theory-driven } \\
\text { research }\end{array}$ & AND & Personalized medicine application & AND & Collection of non-traditional data source \\
\hline $\begin{array}{l}\text { Keywords: theory, } \\
\text { construct. }\end{array}$ & AND & $\begin{array}{l}\text { PubMed Medical Genetics Search } \\
\text { Filter Categories[28]: diagnosis, } \\
\text { differential diagnosis, clinical } \\
\text { description, management, genetic } \\
\text { counseling, molecular genetics, } \\
\text { genetic testing. }\end{array}$ & AND & $\begin{array}{l}\text { Keywords and Mesh terms: telemedicine, telehealth, telesurveillance, social } \\
\text { media, blogging, crowdsourcing, mobile applications, cell phones, handheld } \\
\text { computers, geographic information systems, global positioning systems, mobile } \\
\text { health, mHealth, eHealth, Facebook, online social network, social networking } \\
\text { site, chat room, chat group, short message service, Web-based questionnaire, } \\
\text { app, personal digital assistant, cell phone, cellphone, cellular phone, cellular } \\
\text { telephone, mobile phone, mobile telephone, smart phone, smartphone, mobile } \\
\text { phone, mobile device, wearable sensor, wearable device, wearable technology, } \\
\text { surveys, questionnaires, momentary assessment, self report. }\end{array}$ \\
\hline
\end{tabular}


Second, we coded the identified literature along six dimensions from the $\mathrm{pUHI}$ framework (see Table 2): attributes of innovation, social system, communication channel, time, task characteristics, and technology characteristics. We also included one additional dimension to capture the theory being used in the research. Last, we analyzed the literature by using a concept matrix to assess the current state of theory-driven analyses being applied to study tools that use non-traditional data sources and to derive directions for future studies.

\section{Results}

A total of 702 references were retrieved from the PubMed search and entered into the selection process. Results of the screening process are described in the Figure 2 flow diagram. First, after review of publication titles and abstracts, 430 publications were considered irrelevant and were excluded from further review. Publications were considered irrelevant according to our screening inclusion and exclusion criteria. Second, the full-texts of the remaining 272 publications were reviewed against the criteria (a study of a tool that used non-traditional data sources, the research was theory-driven in relation to the tool, and there was a personalized medicine application), which excluded another 264 publications. One exception was that randomized controlled trials for which study participants were randomized to use of a technology was considered theory-driven in relation to the technology. Overall, the search of the literature identified eight articles that reported theory-driven research on the use of a technology or instrument that uses non-traditional data sources for a personalized medicine application.

A concept matrix was created to summarize insights gained from the literature (Table 3 ). In the following, we present the details of our analysis that led to the creation of Table 3. With regard to the attributes of innovation, we considered Roger's characteristics on the adoption of an innovation [25]: relative advantage, compatibility, complexity, trialability, and observability of the innovation were described. For two of the articles [29,

Table 2 Coding dimensions informed by theoretical domains from the pUHI framework.

\begin{tabular}{|c|c|c|}
\hline $\begin{array}{l}\text { Theoretical } \\
\text { domain }\end{array}$ & Analysis categories & Characteristics within the categories \\
\hline \multirow{4}{*}{$\begin{array}{l}\text { Diffusion of } \\
\text { innovations }\end{array}$} & Attributes of innovation & $\begin{array}{l}\text { Relative advantage, compatibility, complexity, trialability, and } \\
\text { observability of the innovation [25] }\end{array}$ \\
\hline & Social system & $\begin{array}{l}\text { Socioeconomic characteristics, norms, expectations, or potential } \\
\text { consequences of an innovation }\end{array}$ \\
\hline & Communication channel & Patient portal, cell phone, FitBit, blog, etc. \\
\hline & Time & Speed of adoption \\
\hline \multirow{2}{*}{$\begin{array}{l}\text { Task- } \\
\text { Technology Fit }\end{array}$} & $\begin{array}{l}\text { Task characteristics (genomic } \\
\text { medicine application) }\end{array}$ & Genetic test ordering, cancer treatment planning, etc. \\
\hline & $\begin{array}{l}\text { Technology characteristics (non- } \\
\text { traditional data collection approach) }\end{array}$ & $\begin{array}{l}\text { Genetic testing turn-around time, cancer treatment pre-visit } \\
\text { education, etc. }\end{array}$ \\
\hline Other & Theory used & Task-technology fit theory \\
\hline
\end{tabular}

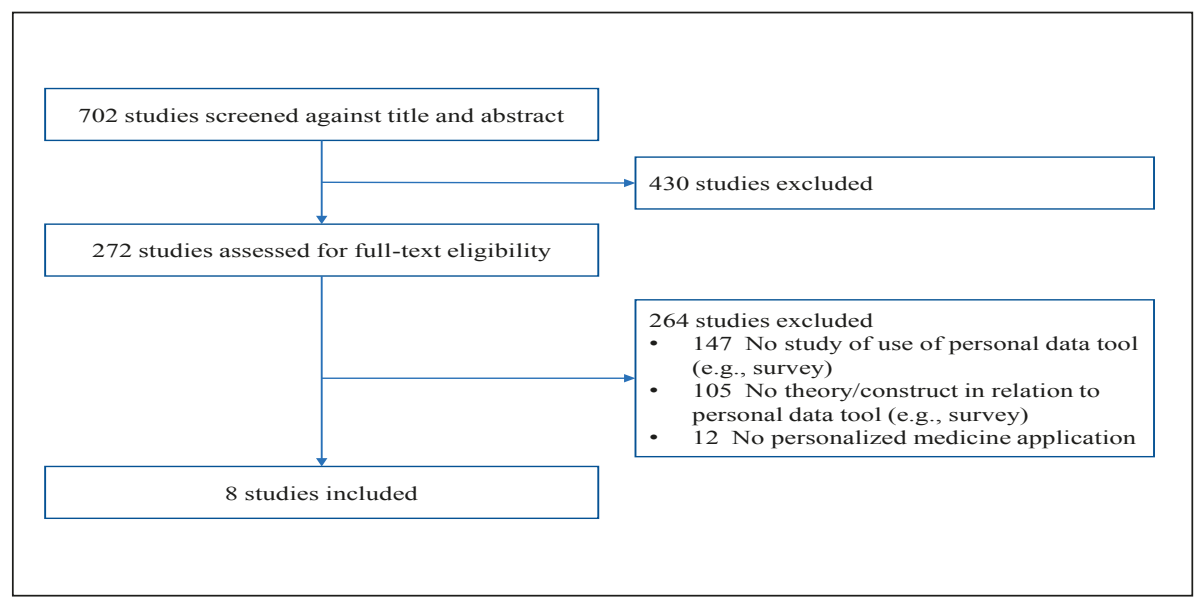

Fig. 2 Flow diagram of the search strategy.

30] a description of attributes was the outcome of the study, five of the articles [31-35] provided a general description of attributes, and one article [36] provided a reference to a description published elsewhere. Concerning the social system, all but one article [29] studied the influence of social system on outcomes. Among those articles, two articles $[30,32]$ studied social system in relation to adopting a tool. Communication channels represented among the eight studies were questionnaires [30, 34], telephone [33, 36], interactive presentation [31], pre-test counseling [32], online risk calculator [35], and online discussion forum [29]. Time to tool adoption was not assessed for any of the reviewed articles. For two articles [30, 32], however, tool adoption was studied as a specific outcome. Task characteristics included tasks for tool use and were targeted to healthcare providers for one article [30], to patients for six articles [29, 31-33, 35, 36], and one article did not have a target end-user [34]. The healthcare provider task was to identify at-risk relatives [30]. Patient tasks included communicating risk to family members [31], making decisions around genetic testing and screening $[32,36]$, understanding genetic 
test results/assessments of risk [33], and making decisions around care coordination [29]. Technology characteristics included technology design characteristics of three tools that were informed by behavior and/ or communication theories [31, 33, 36]. Four tools were used to directly characterize personal health status $[32,34,35]$ or the health status of relatives [30]. One tool enabled unstructured communication [29]. The theory-driven approaches used in the reviewed studies included randomized controlled trials [31, 36], Normalization Process Theory (NPT) [30], Multidimensional Measure of Informed Choice (MMIC) [32], Self-Regulation Model of Health Behavior (SRTHB) [33], Rasch Unidimensional Measurement Model [34], Theory of Planned Behavior [35], and Planning Theory of Communication [29].

\section{Discussion}

The goal of this biomedical literature analysis was to examine the current state of theory-driven research on tools that collect and use non-traditional data in personalized medicine applications and to provide direction for future work. The PubMed search was limited to articles published between 2014 and 2018 to focus on recently developed and published efforts. Nonetheless, there may be relevant publications before 2014 or in other databases (e.g., ACM digital library) that were missed. For example, our approach identified studies that use theory-driven approaches such as NPT, but we did not identify studies that used popular technology acceptance theories such as TAM. In order to confirm if a gap exists, a complementary survey of the literature might study published articles that specifically use technology acceptance theories to measure the adoption and use of personalized medicine applications more broadly (without the focus on collection and use of non-traditional data).

In addition, our search strategy did not identify some studies due to our focus on the direct application of theory to study the adoption of tools. For example, one effort of relevance that was missed is the $\mathrm{NIH}$ National Human Genome Research Institute
(NHGRI)-funded Implementing GeNomics In pracTicE (IGNITE) Network that supports the development of strategies to incorporate genomic information into clinical care, and also the exploration of methods for effective implementation, diffusion, and sustainability of those strategies in diverse clinical settings [37]. Through the Network, sites have adopted the Consolidated Framework for Implementation Research (CFIR) [38] to guide their evaluation of genomic medicine interventions and have identified common strategies to address implementation challenges $[39,40]$. They do not assume specific relationships between individual constructs and outcomes so that commonalities and differences in implementation strategies across projects that have diverse outcomes can be identified.

Another limitation of our approach is that there are some concepts relevant to adoption that may have been missed by the proposed pUHI framework. For example, while DOI theory provides several innovation-related constructs that are relevant to healthcare technology adoption such as relative advantage and compatibility [41], trust is an important element of adopting personalized medicine applications that is not covered. Indeed, it is well-known that trust plays an important role in both adoption of healthcare technologies by clinicians (e.g., due to a perceived threat to their professional autonomy [42]) and by patients (e.g., due to privacy concerns [43]). Extensions of the pUHI framework should be considered to include trust as well as other factors as the role on end-user acceptance is clarified.

Overall, we found only eight publications that fit our criteria. Given our use of PubMed, this may indicate a lack of work published in biomedical journals that study the adoption of personalized medicine applications that use non-traditional data. This is not surprising given our targeted search and also that previous characterization of the scientific literature and federally funded grants found that the majority of genomic research falls within the translational research discovery phase (T0) and the phase where candidate genomic applications are characterized and developed (T1) [44]. Less than $2 \%$ of research falls within phase 2-4 research (T2-4) that attempts to translate genomic discovery into real-world settings and improve population health outcomes [45]. Furthermore, a recent systematic review of T2-4 research found that very few studies incorporated implementation science theoretical models [46]. Similarly, when assessing studies that evaluated IT-based applications in healthcare, most did not discuss a specific theory being applied [47].

In addition, the few articles that fit our criteria may also reflect a lack in the use of non-traditional data sources for personalized medicine research and practice. In order to enable personalized risk assessments from non-traditional data sources, there were several challenges, largely due to the reliability of those data that should be overcome. Many potential sources for more data-driven applications (artificial intelligence and machine learning algorithms) were highly unstructured and had variable quality depending on the source (e.g., online health forums). Moreover, properly describing the environment context for such applications remains a challenge. Proposed solutions to this problem included incorporating the review of input data by domain experts given that those data can contain biases; conducing prospective clinical trials with diverse patient populations to help address potential racial bias due to the use of historical data; and continually calibrating models with human feedback [48].

We also found that while articles covered in this review had personalized medicine applications, the majority of the approaches did not involve the direct collection and use of genetic data. This is consistent with the view that collection of genetic data clinically is still inhibited by cost and availability of facilities required to handle the clinical genomic sequencing of the large number of patients needed to impact population-level risk modeling [49]. There are, however, several large efforts that are studying the value of clinical genomics with other data types such as the NIH-funded All of Us program that is obtaining access to electronic health records and collecting personal genetic, lifestyle, and environmental data to determine relationships to health and disease [50].

Based on our assessment, we propose four directions for future research (Table 4):

a) We need more studies on the influence of innovation and of societal structure on the adoption of strategies that use non-tradi- 


\begin{tabular}{|c|c|c|c|c|c|c|c|c|}
\hline 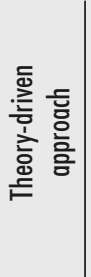 & 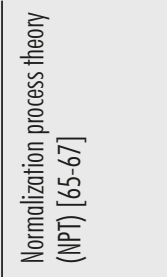 & 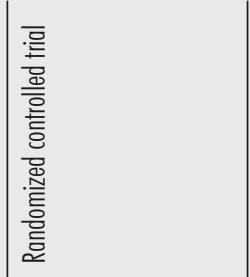 & 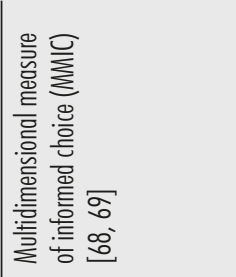 & 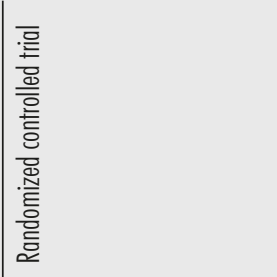 & 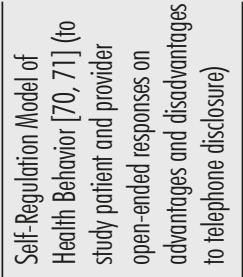 & 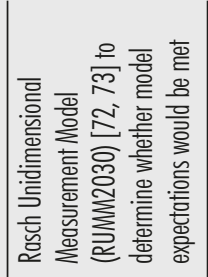 & 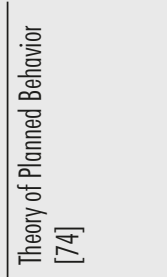 & 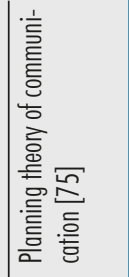 \\
\hline 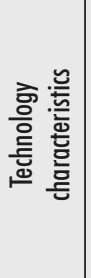 & 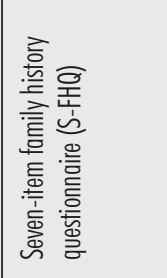 & 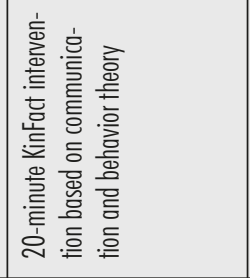 & 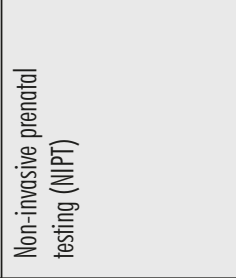 & 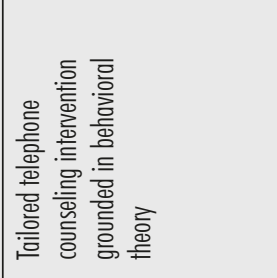 & 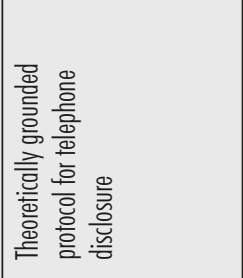 & 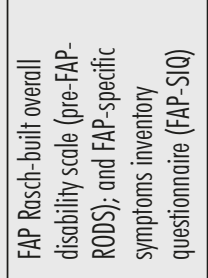 & 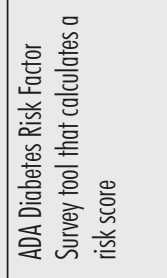 & 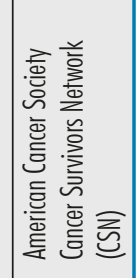 \\
\hline 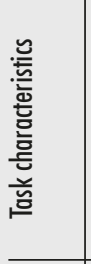 & 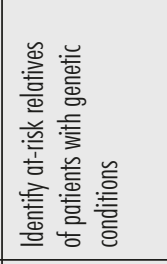 & 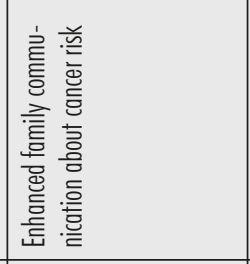 & 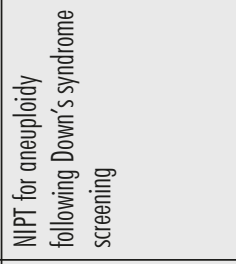 & 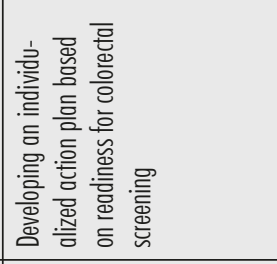 & 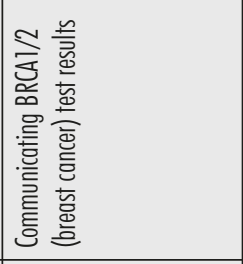 & 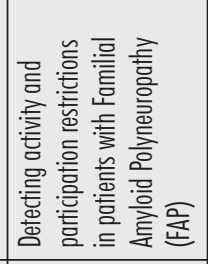 & 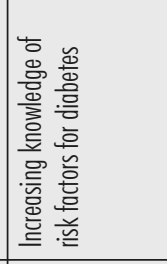 & 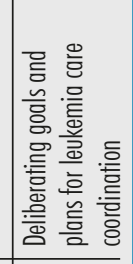 \\
\hline 宦 & 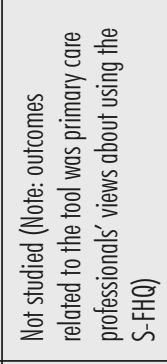 & 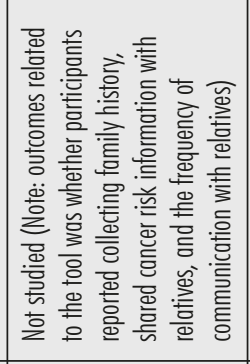 & 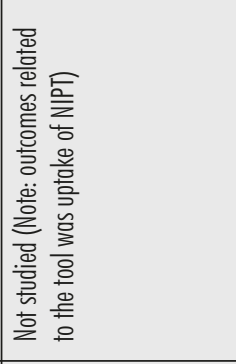 & 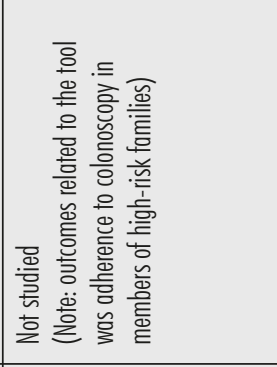 & 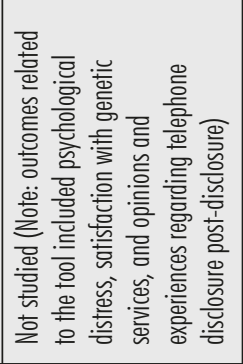 & 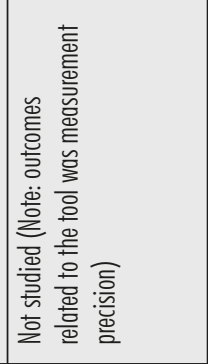 & 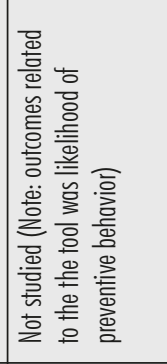 & 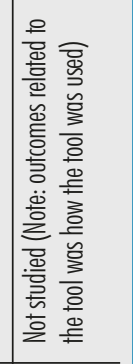 \\
\hline 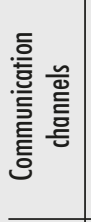 & 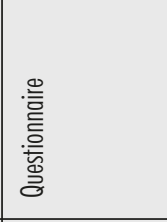 & 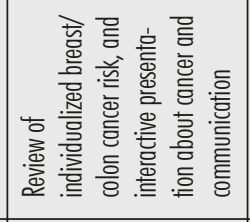 & 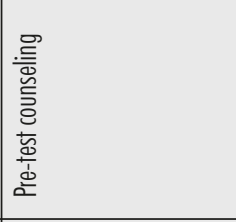 & 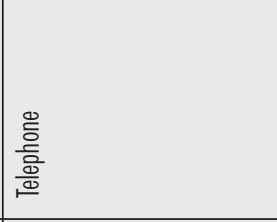 & 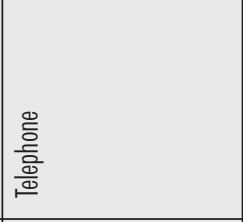 & 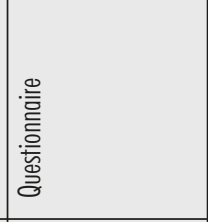 & 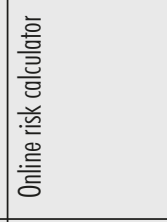 & 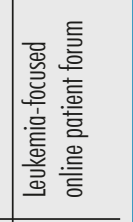 \\
\hline 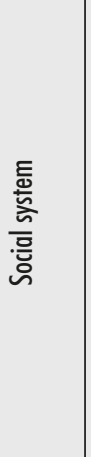 & 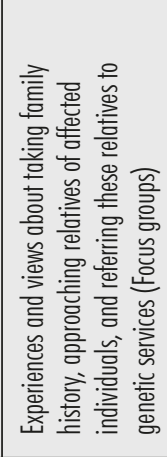 & 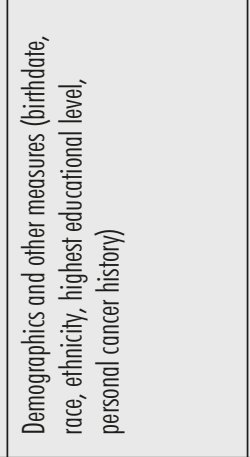 & 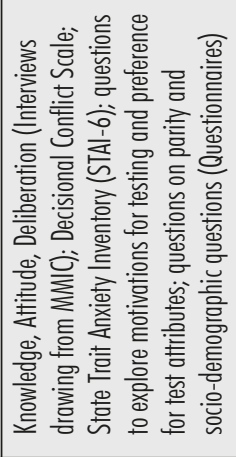 & 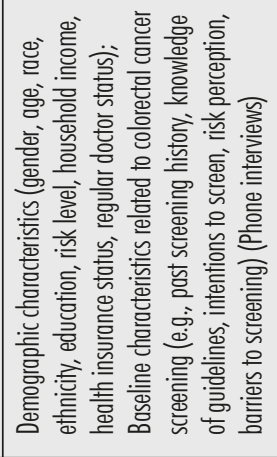 & 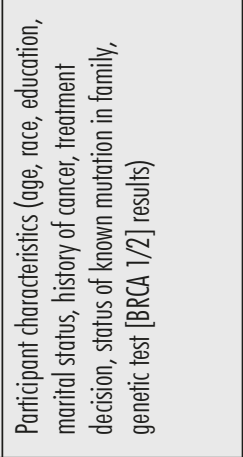 & 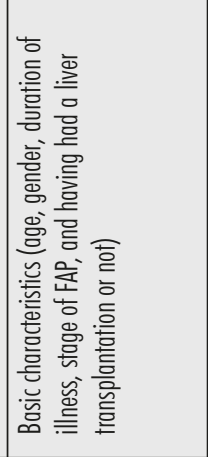 & 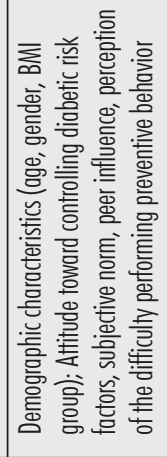 & $\mid$ \\
\hline 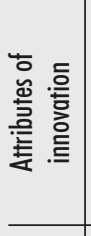 & 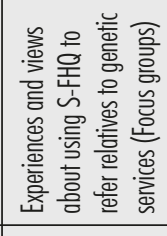 & 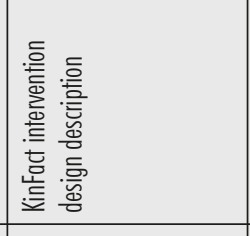 & 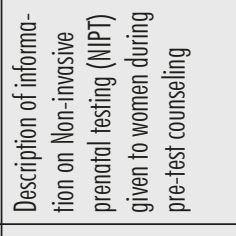 & 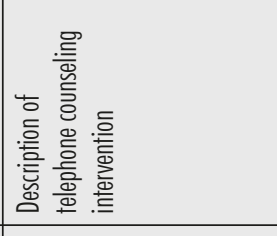 & 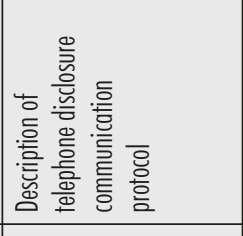 & 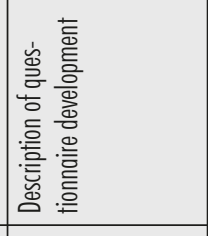 & 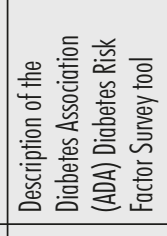 & 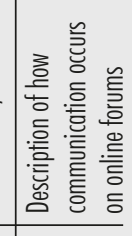 \\
\hline 楚 & 㐫 & $\overline{\bar{m}}$ & $\widetilde{ల ్ ల}$ & চ্ল্ল & 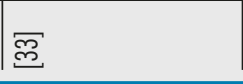 & 密 & 鸪 & 离 \\
\hline
\end{tabular}


tional data in personalized medicine applications. We found that few studies measure attributes of innovation at baseline. According to pUHI framework, such characteristics influence how rapidly an innovation can be adopted. In addition, while the majority of studies we identified collected data on social system, only two studied social system in relation to adoption. Indeed, the adoption of technologies that collect and use non-traditional data sources for personalized medicine (e.g., FitBit for quantified self-tracking, social networks for physician Q\&A) will be strongly influenced by social system (e.g., social value systems, status [e.g., socio-economic levels], cultural backgrounds, etc). As evidenced by others, such factors can lead to variations in adoption and use, which in turn can shape social inequalities in health [12]. These contextual variations due to social system highlight a need to capture how various technologies are accessed and used. These are important aspects of data context [51] that are important for measuring the quality of personalized medicine applications leveraging those data. There is also a need to provide multiple channels of communication to account for a range of societal structures.

b) We need new study designs that allow flexible communication channels while still preserving the ability to study health outcomes of interest. Effective communication can help to answer questions, build familiarity and increase the appeal of an innovation or new strategy. Enabling multiple communication channels can influence how quickly a strategy is shared in different communities and can improve adoption. One such study is the NIH-funded IMAGene (Individualized Medicine through Application of GENomics) clinical trial [52] that is evaluating genomic screening in Ashkenazi Jewish and Hispanic communities. In order to find the best way to communicate information about genetic screening, study participants can decide if they want to use self-guided learning via mailed paper and DVD, or web-portal education. Participants can switch at any time and always have access to a genetic counselor. The value of measuring adaptation is already evident as it relates to health IT adoption
[53]. Similarly, enabling the flexibility to adapt communication processes allows different approaches to be tested and has potential to maximize adoption. With new study designs, tracking the progress of how effective different communication channels are, can make a greater impact by providing lessons that others can draw from when establishing implementation and dissemination strategies with similar interventions.

c) Third, we can become active in personalized medicine implementation and dissemination by creating and studying interventions in healthcare settings. Health information systems such as computer-based patient records, EHRs, telemedicine, and decision support systems are common areas of biomedical informatics research [47]. Furthermore, these technologies are changing patient-provider communication by enabling patients to ask questions, request medication refills, and obtain test results electronically. While there is recognition that such systems can be of value to accelerate personalized medicine practices, there have been few studies that demonstrate integration into clinical settings in a scalable way (e.g., genomic clinical decision support [54]). Drawing from the work of others studying the adoption of health information systems
[55], in order to avoid deploying systems that are not feasible or acceptable for use in practice, studies should also provide a forum for end-users to play a role.

d) Translational informatics scholarship can make a greater impact if it goes beyond data-driven research to conducting theory-driven research with interventions based on algorithms and risk scores that combine genetics and non-genetics factors. Research in this area involves more engagement with health care practice in order to understand the consequences of using those interventions across contexts and time. One area for more theory-driven research is in comparing outcomes and acceptability of different formats for delivering clinical guidance based on algorithms and risk scores. This is an area of importance highlighted by three main trends: (i) the goal for interventions to reach diverse populations that may have varying levels of comprehension in response to different delivery formats [56]; (ii) the recent move to alternative models to provide genomic information to patients [57-59]; and (iii) a growing focus on outcomes that are of most value to patients [60]. Such efforts would contribute to the growing literature reporting findings from studying the return of genetic test results [61-64].

Table 4 Research directions and rationale.

\begin{tabular}{|c|c|c|}
\hline Direction & Description & Rationale \\
\hline $\begin{array}{l}\text { (a) Investigate attributes of } \\
\text { innovation and of societal } \\
\text { structure. }\end{array}$ & $\begin{array}{l}\text { Study the interaction of attributes of innova- } \\
\text { tion with the adoption of strategies that use } \\
\text { non-traditional data sources. }\end{array}$ & $\begin{array}{l}\text { No study investigated attributes of innova- } \\
\text { tion, and only two studied societal structure } \\
\text { in relation with outcomes. }\end{array}$ \\
\hline $\begin{array}{l}\text { (b) Conduct studies that } \\
\text { compare and contrast } \\
\text { communication channels. }\end{array}$ & $\begin{array}{l}\text { Allow more flexibility in communication } \\
\text { channels to enable the formulation of design } \\
\text { principles for implementation. }\end{array}$ & $\begin{array}{l}\text { Two studies investigated multiple commu- } \\
\text { nication channels as part of a randomized } \\
\text { controlled trial. No study enabled study } \\
\text { participants to choose their preferred } \\
\text { communication channel. }\end{array}$ \\
\hline $\begin{array}{l}\text { (c) Create and investigate } \\
\text { personalized medicine interven- } \\
\text { tions in healthcare settings. }\end{array}$ & $\begin{array}{l}\text { Explore interventions within healthcare } \\
\text { settings in order to shed light on patient and } \\
\text { provider perceptions (e.g., access to provid- } \\
\text { ers) and impact (e.g., provider workload). }\end{array}$ & $\begin{array}{l}\text { Only one study of a tool targeted to } \\
\text { healthcare providers and assessed within a } \\
\text { healthcare setting. None targeted to both } \\
\text { healthcare providers and patients. }\end{array}$ \\
\hline $\begin{array}{l}\text { (d) Conduct theory-driven } \\
\text { research with data-driven } \\
\text { interventions. }\end{array}$ & $\begin{array}{l}\text { Expand research on data-driven interventions } \\
\text { to also include theory-driven implementation } \\
\text { and dissemination research. }\end{array}$ & $\begin{array}{l}\text { Only one study involved the use of a calcula- } \\
\text { tion with measures from multiple sources. }\end{array}$ \\
\hline
\end{tabular}




\section{Conclusion}

This work offers two contributions. First, we introduced to an informatics audience an elaboration on personalized medicine implementation with non-traditional data sources by blending it with the personalized medicine unsolicited health information (pUHI) conceptual framework to help explain adoption. We believe that this supports a new line of informatics inquiry that will enable gaining a richer understanding of how personalized medicine interventions disseminate. Second, we highlighted the need for: more research on the relationship between attributes of innovation and of societal structure on adoption; new study designs to enable flexible communication channels; more work to create and study approaches in healthcare settings; and more theory-driven studies with data-driven interventions. With the explosive growth in availability of health data captured using non-traditional sources, these are areas where biomedical informatics scholars can increase their influence on personalized medicine as it becomes more informed by those data sources.

\section{Acknowledgements}

The authors gratefully acknowledge Rob Wright, MLS (Johns Hopkins University, Welch Medical Library) for his contributions to the development of a search strategy for this literature assessment.

\section{References}

1. Allen CG, Andersen B, Khoury MJ, Roberts MC. Current Social Media Conversations about Genetics and Genomics in Health: A Twitter-Based Analysis. Public Health Genomics 2018;21(12):93-9.

2. Ross E, Swallow J, Kerr A, Cunningham-Burley S. Online accounts of gene expression profiling in early-stage breast cancer: Interpreting genomic testing for chemotherapy decision making. Health Expect 2019;22(1):74-82.

3. Piwek L, Ellis DA, Andrews S, Joinson A. The Rise of Consumer Health Wearables: Promises and Barriers. PLoS Med 2016;13(2):e1001953.

4. Riley WT, Nilsen WJ, Manolio TA, Masys DR, Lauer M. News from the NIH: potential contributions of the behavioral and social sciences to the precision medicine initiative. Transl Behav Med 2015;5(3):243-6

5. Torkamani A, Andersen KG, Steinhubl SR, Topol EJ. High-Definition Medicine. Cell
2017;170(5):828-43.

6. Lautenbach DM, Christensen KD, Sparks JA, Green RC. Communicating genetic risk information for common disorders in the era of genomic medicine. Annual Rev Genomics Hum Genet 2013;14:491-513.

7. Kullo IJ, Jouni H, Austin EE, Brown SA, Kruisselbrink TM, Isseh IN et al. Incorporating a Genetic Risk Score Into Coronary Heart Disease Risk Estimates: Effect on Low-Density Lipoprotein Cholesterol Levels (the MI-GENES Clinical Trial). Circulation 2016;133(12):1181-8.

8. Zhu H, Colgan J, Reddy M, Choe EK. Sharing Patient-Generated Data in Clinical Practices: An Interview Study. AMIA Annu Symp Proc 2016;2016:1303-12.

9. Cohen DJ, Keller SR, Hayes GR, Dorr DA, Ash JS, Sittig DF. Integrating Patient-Generated Health Data Into Clinical Care Settings or Clinical Decision-Making: Lessons Learned From Project HealthDesign. JMIR Hum Factors 2016;3(2):e26.

10. 2017 AMIA Policy Invitational. Redefining Our Picture of Health: Towards a Person-Centered Integrated Care, Research, Wellness, and Community Ecosystem. Available from: https://www.amia. org/sites/default/files/API-2017-White-PaperRedefining-our-Picture-of-Health.pdf [Accessed 11 Feburary 2019].

11. Haendel MA, Chute CG, Robinson PN. Classification, Ontology, and Precision Medicine. N Engl J Med 2018;379(15):1452-62.

12. Weiss D, Rydland HT, Oversveen E, Jensen MR., Solhaug, S., and Krokstad, S. Innovative technologies and social inequalities in health: A scoping review of the literature. PloS One 2018;13(4):e0195447.

13. Hollister B, Bonham VL. Should Electronic Health Record-Derived Social and Behavioral Data Be Used in Precision Medicine Research? AMA J Ethics 2018;20(9):E873-80.

14. De La Vega FM, Bustamante CD. Polygenic risk scores: a biased prediction? Genome Med 2018;10(1):100.

15. Khoury MJ, Gwinn M, Yoon PW, Dowling N, Moore CA, Bradley L. The continuum of translation research in genomic medicine: how can we accelerate the appropriate integration of human genome discoveries into health care and disease prevention? Genet Med 2007;9(10):665-74.

16. Maass W, Parsons J, Purao S, Storey VC, Woo C. Data-driven meets theory-driven research in the era of big data: opportunities and challenges for information systems research. Journal of the Association for Information Systems 2018,19(12):1253-73.

17. Chambers DA, Feero WG, Khoury MJ. Convergence of Implementation Science, Precision Medicine, and the Learning Health Care System: A New Model for Biomedical Research. JAMA 2016;315(18):1941-2.

18. Dearing JW. Applying Diffusion of Innovation Theory to Intervention Development. Res Soc Work Pract 2009;19(5):503-18.

19. Davis F. User acceptance of information technology: system characteristics, user perceptions and behavioral impacts. Int J Man Mach Stud
1993;38(3):475-87.

20. Tavares J, Oliveira T. Electronic Health Record Patient Portal Adoption by Health Care Consumers: An Acceptance Model and Survey. J Med Internet Res 2016;18(3):e49.

21. Rahimi B, Nadri H, Lotfnezhad Afshar H, Timpka T. A Systematic Review of the Technology Acceptance Model in Health Informatics. Appl Clin Inform 2018;9(3):604-34.

22. Holden RJ, Karsh BT. The technology acceptance model: its past and its future in health care. J Biomed Inform 2010;43(1):159-72.

23. Moore GC, Benbasat I. Development of an instrument to measure the perceptions of adopting an information technology innovation. Information Systems Research 1991;2(3):192-222.

24. Overby CL, Devine EB, Abernethy N, McCune JS, Tarczy-Hornoch P. Making pharmacogenomic-based prescribing alerts more effective: A scenario-based pilot study with physicians. J Biomed Inform 2015;55:249-59.

25. Rogers EM. Diffusion of innovations. Simon and Schuster; 2010.

26. Goodhue DL, Thompson RL. Task-technology fit and individual performance. MIS Q 1995;213-36.

27. Massey AP, Montoya-Weiss M, Hung C, Ramesh V. Cultural perceptions of task-technology fit. Communications of the ACM 2001:44(12):83-4.

28. PubMed Clinical Queries Filters [Internet]. Available from: https://www.ncbi.nlm.nih.gov/ books/NBK3827/\#pubmedhelp.Clinical_Queries_Filters. Secondary PubMed Clinical Queries Filters [Internet]. Available from: https://www. ncbi.nlm.nih.gov/books/NBK3827/\#pubmedhelp. Clinical_Queries_Filters 2005-

29. Strekalova YA, Hawkins KE, Drusbosky LM, Cogle CR. Using social media to assess care coordination goals and plans for leukemia patients and survivors. Transl Behav Med 2018;8(3):481-91.

30. Ahmed S, Hayward J, Ahmed M. Primary care professionals' perceptions of using a short family history questionnaire. Family Pract 2016;33(6):704-08

31. Bodurtha JN, McClish D, Gyure M, Corona R, Krist AH, Rodríguez VM, et al. The KinFact intervention - a randomized controlled trial to increase family communication about cancer history. J Womens Health (Larchmt) 2014;23(10):806-16.

32. Lewis C, Hill M, Skirton H, Chitty LS. Development and validation of a measure of informed choice for women undergoing non-invasive prenatal testing for aneuploidy. Eur J Hum Genet 2016;24(6):809-16.

33. Patrick-Miller LJ, Egleston BL, Fetzer D, Forman A, Bealin L, Rybak C, et al. Development of a communication protocol for telephone disclosure of genetic test results for cancer predisposition. JMIR Res Protoc 2014;3(4):e49.

34. Pruppers MH, Merkies IS, Faber CG, Da Silva A., Costa V, Coelho T. The Val30Met familial amyloid polyneuropathy specific Rasch-built overall disability scale (FAP-RODS((c)) ). J Peripher Nerv Syst 2015;20(3):319-27.

35. Seaborn C, Suther S, Lee T, Kiros GE, Becker A, Campbell E, et al. Utilizing Genomics through Family Health History with the Theory of Planned Behavior: Prediction of Type 2 Diabetes Risk Factors and Preventive Behavior in an African 
Personalized Medicine Implementation with Non-traditional Data Sources: A Conceptual Framework and Survey of the Literature

American Population in Florida. Public Health Genomics 2016;19(2):69-80.

36. Lowery JT, Horick N, Kinney AY, Finkelstein DM, Garrett K, Haile RW, et al. A randomized trial to increase colonoscopy screening in members of high-risk families in the colorectal cancer family registry and cancer genetics network. Cancer Epidemiol Biomarkers Prev 2014;23(4):601-10.

37. Weitzel KW, Alexander M, Bernhardt BA, Calman N, Carey DJ, Cavallari LH, et al; IGNITE Network. The IGNITE network: a model for genomic medicine implementation and research. BMC Med Genomics 2016;9:1.

38. Damschroder LJ, Aron DC, Keith RE, Kirsh SR, Alexander JA, Lowery JC. Fostering implementation of health services research findings into practice: a consolidated framework for advancing implementation science. Implement Sci 2009;4:50.

39. Orlando LA, Sperber NR, Voils C, Nichols M, Myers RA, Wu RR, et al. Developing a common framework for evaluating the implementation of genomic medicine interventions in clinical care: the IGNITE Network's Common Measures Working Group. Genet Med 2018;20(6):655-63.

40. Sperber NR, Carpenter JS, Cavallari LH, J Damschroder L, Cooper-DeHoff RM, Denny JC, et al. Challenges and strategies for implementing genomic services in diverse settings: experiences from the Implementing GeNomics In pracTicE (IGNITE) network. BMC Med Genomics 2017;10(1):35.

41. Varabyova Y, Blankart CR, Greer AL, Schreyogg J. The determinants of medical technology adoption in different decisional systems: A systematic literature review. Health Policy 2017;121(3):230-42.

42. Walter Z, Lopez MS. Physician acceptance of information technologies: Role of perceived threat to professional autonomy. Decis Support Syst 2008;46(1):206-15.

43. Angst CM, Agarwal R. Adoption of electronic health records in the presence of privacy concerns: The elaboration likelihood model and individual persuasion. MIS Q 2009;33(2):339-70.

44. Schully SD, Khoury MJ. What is translational genomics? An expanded research agenda for improving individual and population health. Appl Transl Genom 2014;3(4):82-83.

45. Clyne M, Schully SD, Dotson WD, Douglas MP, Gwinn M, Kolor K, et al. Horizon scanning for translational genomic research beyond bench to bedside. Genetics in medicine : official journal of the American College of Medical Genetics 2014;16(7):535-8.

46. Roberts, M.C., Kennedy, A.E., Chambers, D.A., and Khoury, M.J. The current state of implementation science in genomic medicine: opportunities for improvement. Genet Medic 2017;19(8):858.

47. Rahimi B, Vimarlund V. Methods to evaluate health information systems in healthcare settings: a literature review. J Med Syst 2007;31(5):397-432

48. Yu KH, Kohane IS. Framing the challenges of artificial intelligence in medicine. BMJ Qual Saf
2019;28(3):238-41.

49. Richter AN, Khoshgoftaar TM. A review of statistical and machine learning methods for modeling cancer risk using structured clinical data. Artif Intell Med 2018;90:1-14.

50. Collins FS, Varmus H. A new initiative on precision medicine. N Engl J Med 2015;372(9):793-5.

51. Context: The missing piece in the machine learning lifecycle. KDD CMI Workshop; 2018.

52. IMAGene: A study for healthy volunteers evaluating how genes affect health risks. Available from: https://recruit.cumc.columbia.edu/clinical_trial/1045. Secondary IMAGene: A study for healthy volunteers evaluating how genes affect health risks. Available from: https://recruit.cumc.columbia.edu/ clinical_trial/1045 2017.

53. Yen PY, McAlearney AS, Sieck CJ, Hefner JL, Huerta TR. Health Information Technology (HIT) Adaptation: Refocusing on the Journey to Successful HIT Implementation. JMIR Med Inform 2017;5(3):e28

54. Welch BM, Kawamoto K. Clinical decision support for genetically guided personalized medicine: a systematic review. J Am Med Inform Assoc 2013;20(2):388-400.

55. O'Donnell A, Kaner E, Shaw C, Haighto, C. Primary care physicians' attitudes to the adoption of electronic medical records: a systematic review and evidence synthesis using the clinical adoption framework. BMC Medi Inform Decis Mak 2018;18(1):101.

56. Haga B, Barry WT, Mills R, Svetkey L, Suchindran $\mathrm{S}$, Willard HF, et al. Impact of delivery models on understanding genomic risk for type 2 diabetes. Public Health Genomics 2014;17(2):95-104.

57. Persky S, Kistler WD, Klein WMP, Ferrer RA. Internet Versus Virtual Reality Settings for Genomics Information Provision. Cyberpsychol Behav Soc Netw 2019;22(1):7-14.

58. Birch PH. Interactive e-counselling for genetics pre-test decisions: where are we now? Clin Genet 2015;87(3):209-17.

59. Birch P, Adam S, Bansback N, Coe RR, Hicklin J, Lehman A, et al. DECIDE: a Decision Support Tool to Facilitate Parents' Choices Regarding Genome-Wide Sequencing. J Genet Couns 2016;25(6):1298-308.

60. Phillips KA, Deverka PA, Sox HC, Khoury MJ, Sandy LG, Ginsburg GS, et al. Making genomic medicine evidence-based and patient-centered: a structured review and landscape analysis of comparative effectiveness research. Genet Med 2017;19(10):1081-91.

61. Hamilton JG, Abdiwahab E, Edwards HM, Fang ML, Jdayani A, Breslau ES. Primary care providers' cancer genetic testing-related knowledge, attitudes, and communication behaviors: A systematic review and research agenda. J Gen Intern Med 2017;32(3):315-24.

62. Rohrer Vitek CR, Abul-Husn NS, Connolly JJ, Hartzler AL, Kitchner T, Peterson JF, et al. Healthcare provider education to support inte- gration of pharmacogenomics in practice: the eMERGE Network experience. Pharmacogenomics 2017;18(10):1013-25.

63. Schmidlen T, Sturm AC, Hovick S, Scheinfeldt L, Scott Roberts J, Morr L, et al. Operationalizing the Reciprocal Engagement Model of Genetic Counseling Practice: a Framework for the Scalable Delivery of Genomic Counseling and Testing. J Genet Couns 2018;27(5):1111-29.

64. Green RC, Goddard KA, Jarvik GP, Amendola LM, Appelbaum PS, Berg JS, et al; Clinical Sequencing Exploratory Research Consortium. Accelerating Evidence-Based Practice of Genomic Medicine. Am J Hum Genet 2016;99(1):246.

65. de Brún T, de-Brún MOR, van Weel-Baumgarten E, van Weel C, Dowrick C, Lionis C, et al. Guidelines and training initiatives that support communication in cross-cultural primary-care settings: appraising their implementability using Normalization Process Theory. Fam Pract 2015;32(4):420-25.

66. May CR, Cummings A, Girling M, , Bracher M, Mair FS, May CM, et al. Using Normalization Process Theory in feasibility studies and process evaluations of complex healthcare interventions: a systematic review. Implement Sci 2018;13(1):80.

67. May C, Finch TJS. Implementing, embedding, and integrating practices: an outline of normalization process theory. Sociology 2009;43(3):535-54.

68. Marteau TM, Dormandy E, Michie S. A measure of informed choice. Health Expect 2001;4(2):99-108.

69. Michie S, Dormandy E, Marteau TM. The multi-dimensional measure of informed choice: a validation study. Patient Educ Couns 2002;48(1):87-91.

70. Leventhal H, Diefenbach M, Leventhal EA. Illness cognition: using common sense to understand treatment adherence and affect cognition interactions. Cognit Ther Res 1992;16(2):143-63.

71. Robitaille C. Illness representations: theoretical foundations. Perceptions of health illness: Current research applications; 1997.

72. Andrich D, Sheridan B, Luo G. Rasch models for measurement: RUMM2030. Perth, Western Australia: RUMM Laboratory Pty Ltd; 2010.

73. Rasch G. Probabilistic models for some intelligence and attainment tests. Copenhagen: Danish Institute for Educational Research; 1960.

74. Ajzen I, Fishbein M. Understanding attitudes and predicting social behaviour. 1980

75. Berger CR. Planning theory of communication: Sage Publications, Inc; 2008.

Correspondence to:

Casey Overby Taylor

2024 E. Monument

Baltimore, MD 21205

USA

Tel: + 14432876657

E-mail:cot@jhu.edu 